\title{
Human Values and Reaction to CSR Announcements: A Cross- National Comparison with Emphasis on U.S.-Global Differences
}

\author{
Marek Pawlak, Sathiadev Mahesh \\ The John Paul II Catholic University of Lublin, Poland \\ University of New Orleans, USA
}

\begin{abstract}
Studies have been conducted in five countries concerning the human values of management students, and their opinions about corporate social responsibility (CSR) initiatives. While the results suggest that CSR announcements have a significant influence on the opinion about company CSR initiatives, we observe a difference between students in the U.S. and students in other countries. The highest negative response to CSR announcements was in the group of self-transcendent students in the USA, and in the group of conservative students in Europe and Asia. On the basis of these studies' results, it is possible to say that there are differences in reactions to CSR announcements depending on cultural (local) circumstances and that companies should not employ direct communication concerning their CSR initiatives.
\end{abstract}

Keywords: Corporate social responsibility (CSR), CSR communication strategies, CSR announcements, Legitimacy theory

\section{Introduction}

In some countries, particularly in Europe, the term Corporate Social Responsibility (CSR) has become fashionable. Companies engage in CSR activity, and include it in their corporate announcements, and even in their brand development strategy. Businesses often communicate their involvement in CSR projects to the local community. However, there are few studies which can be used to determine the value of these communications. Does this message improve people's opinion about CSR, or does it make it worse? Is it profitable for companies to inform people about CSR activities, or not? In particular, in this paper, we study U.S. students and measure the differences in opinions. The conclusions of this study point to differences in CSR opinions in the U.S. and suggest that corporate managers need to evaluate the cultural context more thoroughly.

People evaluate CSR in various ways. Former studies suggest that CSR announcements are evaluated more positively by women than men (Evans, Davis, 2011; Smith et al., 2001; Groves and LaRoca, 2012; Wang and Juslin, 2012), increase with self-perceived religiousness (González-Rodríguez, et al., 2013), and are impacted by societal and cultural values (Wang and Juslin, 2012, González-Rodríguez et al., 2013). We have investigated the link between cultural background, personal values, the perception of CSR and the response to companies' CSR announcements in the USA. The results are compared to earlier published results based on tests of students in Europe (Poland) and Asia (Taiwan) reported in González-Rodríguez et al. (2013). The USA students are business majors working part-time and attend a large public university in a metropolitan area. Similar to the earlier study, studentswere provided with two versions of the CSR announcement; one, which had no corporate promotion, and the other, which promoted the company's role in the CSR effort. The case study was altered to suit the local environment. 


\section{Theoretical background}

\subsection{Personal values as a driver of human actions}

The human value construct

Human values influence the behaviour of individuals and groups. Smith et al., (2001) cite the definition of human values formulated by Clyde Kluckhohn in 1951: "a value is a conception explicit or implicit, distinctive of an individual or characteristic of a group, of the desirable which influences the means and ends of action". Fritzsche and $\mathrm{Oz}$ (2007) and Wang and Juslin (2012) argue that the personal values of an individual are based on the belief that a particular mode of conduct or outcome is preferable to other modes of conduct and outcomes. Evans \& Davis (2011), and Smith et al. (2001) provide the basis for the development of individual attitudes that lead to specific decisions and behaviours. Glazer and Beehr (2002) explain that human values may develop from basic biological needs or from group welfare needs.

Regardless of their origin, human values influence behaviour by providing justifications for past behaviour and encouragement for future behaviour (Glaser, Daniel, Short, 2004, Groves and La Rocca, 2012). They can explain individual and group attitudes, and behaviour (Davidov, De Beuckelaer, 2010). Evans and Davis (2011) show that human values act by a filtering mechanism, determining which facts receive attention, and which facts are ignored from consideration. While attitudes, motives, and traits can impact behaviour, values serve as guiding principles in life (Roccas et al. 2002). Values cannot be directly seen or heard and can be measured by the way in which they impact preferences, decisions, and actions (Van der Wal and Hubersta, 2008). However, Koivula (2008) concludes that there is disagreement over what values are, because they can be expressed in different forms, such as principles, beliefs, standards, or tendencies, and they can change over time with aging and education.

One of the best-known theories describing human values is the concept proposed by Shalom Schwartz (2006). According to this concept, values are "the criteria people use to evaluate actions, people and events" (Schwartz 2006). Values are defined as trans-situational goals which serve as a guiding principle (Schwartz and Sagie, 2000), and a modifier of behaviour (Bardi and Schwartz, 2003), impacting daily behaviour in a range of settings (Sagiv and Schwartz, 2004).

According to Schwartz, there are ten basic values grouped into four higher-order value types; self-enhancement, openness to change, self-transcendence, and conservation. Self-enhancement is composed of social control over others, personal success, and personal pleasure. Openness to change includes the need for stimulation by new thrills and challenges and self-direction which is the ability to chart an independent path and choose freely. Self-transcendence is based on universalism which includes social responsibility and tolerance for others, and benevolence which is the enhancement of the welfare of other members in the group. Conservation includes tradition which is the continuity of customs and ideas, conformity which is restraining actions within group norms, and security which is maintaining social stability. Strong empirical support for Schwartz's conclusion has been provided by studies conducted in over 60 countries (Perrinjaquet et al., 2007). Fischer and Schwartz (2011) claim that value priorities show more agreement than disagreement across countries.

\section{Measuring Schwartz's Value priorities}

The primary instrument to measure values based on Schwartz's theory was the Schwartz Value Survey (SVS). This questionnaire consists of two lists of value items (30 and 26 values respectively). Each item expresses one aspect of the motivational goal of one value. Respondents rate the importance of each value item on a 9-point scale from -1 to 7 (Struch et al., 2002). The SVS has been translated into 47 languages (Schwartz, 2006). The Portrait Values Questionnaire (PVQ), and ESS questionnaire, alternatives to SVS, were developed to measure values with subjects who were not familiar with abstract questionnaires (Liem, Martin, Nair, Bernardo, Prasetya, 2011, Knoppen and Saris, 2009). The PVQ provides a questionnaire that can be easily translated into different languages, and retain its robustness. 


\subsection{Opinions about CSR}

The CSR concept

Does a business have corporate responsibility to social issues? CSR programs are essential if there is a widely held belief in society that profit-making corporations should work for social benefit (Birth, et al. 2008). Friedman (1970) however argues that while individuals have responsibilities to family and society, business has only a responsibility to make profits. He views CSR analyses as lacking analytical rigor since they are often driven by the need to appear respectable in society, especially to critics of for-profit business. Cynics of CSR continue to argue that CSR is hypocritical and useless (Boulstridge and Carrigan, 2000, Quairel-Lanoizelée, 2011). CSR as a concept has been perceived as fuzzy, unclear and contested (Amaeshi and Adi, 2007). Despite this critical approach, there are many positive attitudes to CSR. While individuals can personally contribute to social welfare, corporate programs provide an avenue to work on social causes outside the workday and may help team-building in innovative organizations (Braccio, 2013).

In addition to the questions of whether there is a need for corporate CSR programs, the definition of CSR is very generic and non-operational (Nielsen, Thomsen, 2007). An example of such a broad definition is the statement of Pomering and Dolnicar (2008) which brings in a grab-bag of terms like "sustainable economic development", and "quality of life".CSR definitions can be divided into four groups (Nielsen, Thomsen, 2009), (Wang and Juslin, 2012) and described in the following manner: (i) CSR is merely a way to enhance reputation and thereby enhance profits, (ii) CSR programs enhance the societal power of corporations, (iii) CSR ensures that the corporation is viewed as a part of society, and this is important since it must operate within that society, (iv) CSR is an ethical responsibility, and the corporation as a large entity can help to achieve a better society.

A business can focus its CSR efforts on philanthropy or be a responsible steward of the environment (Ellen, Webb, Mohr, 2006). It can focus on society's "expectations of the day" (Reynolds and Yuthas, 2007), or the expectation of powerful stakeholders (Vanhamme and Grobben, 2008), and the need to contribute to the community (Hartment, et. al 2007). Arvidsson (2010) argues that CSR is primarily motivated by the desire to prevent a negative view of the company, which can impact corporate profitability. CSR may be driven by the need to display a public image different from that of a purely profit driven business (Pomering, Johnson, 2009, 2), or may just be another approach to promoting the services and products of the business (Vanhamme and Grobben, 2008). Some authors stressed that CSR encompass discretionary activities that are not mandated by law (Kotler and Lee, 2005, p. 3), (European Commission, 2002), (Runhaar and Lafferty, 2008), (Buhmann, 2006) and are actions which are beyond economic criteria (Pomering and Johnson, 2009, 1).

\section{Values as a source of CSR actions}

If neither legal nor economic criteria are the motivation for CSR, values become the primary factor that influences CSR initiatives of companies. CSR can be viewed as the "right thing to do" and closely related to the "corporation's values" (Hartman et al., 2007), which may be derived from the personal values of the founder of the business. It may be driven by socially responsible investors basing investment decisions on their personal values and demanding that corporate investments be used in a manner consistent with their values (Roberts, Rapson, and Shiers, 2007).

The response to the firm and its CSR program was the most positive when consumers attributed both value-driven and strategic motives to the firm (Ellen, Web, Mohr, 2006). Hence customers will be positive to a CSR program with which the business has been identified for a long time, and with programs introduced before negative information about the company is released (Groza et al. 2011). From this perspective, companies may engage in CSR as a potential insurance against future damaging information (Vanhamme and Grobben, 2008).

\section{CSR communication}

Does a communication about corporate CSR activity have any value? When viewing a CSR communication as part of a communication toolset (Golob et al. 2013), it is merely one of many possible communication channels. A business could follow the rule of not talking about its own good deeds (Moreau, Parguel, 2011), based on religious prescriptions. Kotler and Lee (2005, p. 250) distinguish two general strategies, "don't be shy", and "let others do the talking". While counter-productive to over-communicate CSR (Tixier, 2003, p. 79), (Nielsen, Thomsen, 2009), stakeholders should be made aware of CSR (Davis, MacDonald, 2010, Chen, Zhang, 2009). 


\section{Consumer scepticism}

Advertising used to communicate CSR initiatives to sceptical customers has proved ineffective (Birth et al. 2008), (Pomering, Dolnicar, 2008). This is exacerbated in the case of CSR projects perceived as incongruent with corporate actions (Vanhamme, Grobben, 2008), (Fassin and Buelens, 2011), and Arvidson (2010). Benoit-Moreau and Parguel (2011) also argue that too many CSR communications are counter-productive. A CSR announcement must include information about long-term commitment to CSR, and benefits not only for society but also for the company, to reduce scepticism.

\section{CSR communication strategies}

There are two CSR communication strategies, discretion and open communication. In the discretionary communication strategy, the business operates CSR programs, but does not communicate openly about the programs. Tixier (2003) states that this is typical of companies in Latin American countries and provides examples of many companies (Auchan, IBM, Suez, Boulanger) who have been involved in CSR activities and did not publicize them. According to Tixier, the discretion may be because of a fear of being suspected of commercial manipulation, public criticism of hypocrisy, or a failure to understand how to communicate about the CSR (Tixier, 2003, p. 76). Overt claims will be viewed as a sham and an attempt to fix problems (Ashforth and Gibb, 1999, p. 188). CSR communication often requires indirect communication through word of mouth, or NGOs (Benoit-Moreau and Parguel, 2011), and the use of a source that is perceived as independent increases the positive impact of CSR campaigns (Swaen and Vanhamme, 2004). Hence Neilsen and Thomsen (2009) recommend the use of informal communication channels. Even company controlled publications can be used for soft communication of CSR initiatives by placing them subtly within a corporate annual report or website (Pomering and Johnson (2009, 2, p. 110). However, depending on cultural values, it may make sense to promote the CSR program more explicitly (Tixier, 2003, Schmeltz, 2012).

\section{Legitimacy theory}

A business should operate within the legal, cultural, and social norms of the society within which it operates (Suchman, 1995, p. 574), (Vanhame and Grobben, 2008), and this is necessary to ensure the very existence of the organization (Farache and Perks, 2010). Business should voluntarily disclose its major actions to be perceived as a legitimate organization (Arvidsson, 2010). While pragmatic legitimacy involves meeting legal and ethical requirements, actions which demonstrate an organization's commitment to social norms support its claim to social legitimacy (Vanhamme and Grobben, 2008). These actions must be taken prior to a crisis (Pomering, Johnson, 2009), or will be viewed as a charade (Fassin and Buelens, 2011).

\section{Hypotheses}

Groves and LaRoca (2012) found that leadership performance outcomes were mediated by CSR beliefs of followers. Evans \& Davis (2011) claim that personal values and education about CSR impact perceptions of the company as a good corporate citizen. Schmeltz (2012) shows that values drive consumer expectations about CSR. According to Schwartz's theory, people's opinions depend on their values. Is this true and does it span cultures or does it change across national cultures? Is this relationship affected by a campaign to promote the CSR initiative? We propose two null hypotheses which reject the impact and verify if our evidence supports or rejects these null hypotheses. H1a suggests that there is no relationship between values and cultures and that there is no difference in the impact across national cultures. H1b suggests that this relationship is not impacted by corporate announcements about the CSR initiative, i.e. there is no advantage or loss from promotion.

H1a: The relationship between people's values and opinions about CSR is the same across cultures HIb: The relationship between people's values and opinions about CSR is not changed by CSR announcements.

If we find evidence to reject these null hypothesis we can conclude that there is an impact of values on CSR opinions and that there is a difference in the relationship between different cultures.

Altruistic people are perceived as being friendlier. Nan and Heo (2007) suggest that altruistic consumers will feel "a sense of connectedness" to a business which, by its actions, demonstrates similar beliefs. A similar argument is made by Evans and Davis (2011) regarding companies which demonstrate co-operation and a social welfare orientation in their 
actions. A campaign to capitalize on the CSR initiative will arouse scepticism about corporate goals, and will likely reduce customer preference for the initiative. This enables us to propose the following hypothesis:

H2: Altruistic customers evaluate CSR initiatives higher than other consumers in all cultures when the initiative is not advertised.

\section{Research method}

In order to study the relationship between people's values and opinions about CSR, and also the response to the CSR announcements, studies were conducted in Europe (Poland), Asia (Taiwan) and the USA. The questionnaire used in the study has three sections.

The first section collects students' selections from a set of statements, about their values. The PVQ was used here. The second section describes a CSR initiative and collects data about respondents' opinions about the CSR initiative. This is a 7-point Likert scale similar to that used by Groza, Pronschinske, and Walker (2011), and Wang and Juslin, (2012). In Europe and Asia the CSR initiative concerned the problem of child malnutrition, and consisted of financial help given to the school canteen in a hypothetical town. In the U.S version, the CSR initiative discussed a three-year program to assist foodbanks and shelters. There are two versions of both questionnaires. In the first, the social initiative was presented, and nothing stated about any CSR announcements by the company. In the second, additional information was includedabout a program of announcements conducted by the company to inform the public about the CSR initiative.

The third section of the questionnaire collected demographic data from the respondent. Demographic data collected in the questionnaire met human subject data collection standards enforced by the university and were approved by the institutional review board. Our data from the USA, Europe (Poland) and Asia (Taiwan) used only business school students. The first and second versions of the completed questionnaires were collected from the following number of respondents in different countries. Poland 350/311, Taiwan 121/124, the USA 55/51.

\section{Results}

Schwartz Theory was used to analyse the results. One question in the first section of the PVQ questionnaire is "He seeks every chance to have fun. It is important to him to do things that give pleasure." The PVQ has 21 such statements. Respondents answered each statement with a response to the question: "How much is the person described like or not like you?". The response to the PVQ questions is used to generate a score on how much the respondents identify themselves with the person described in the statement.

In previous studies respondents were divided into four groups: self-enhanced, open to change, self-transcendent, conservative. González-Rodríguez et al. (2013) used the K-means cluster analysis for the group assignment, but it is difficult to interpret the groups obtained when using their approach. Wang and Juslin (2012) used both the EFA and CFA methods. The actual computations process is two-step, with average assessments calculated amongst the ten basic values as the first step. We then calculate averageassessments for the four higher order values from these assessments. Rather than attempt to pigeonhole our subjects into a values category as in previous studies, we find the relationship between their scores on the four dimensions of values, self-enhanced, open to change, self-transcendent, and conservative, and their preference for CSR, when there is no explicit advertisement for the program and when there is a corporate communication channel to "sell" the CSR program.

We argue that categorizing customers into clearly defined categories is prone to error for a number of reasons. The first problem in categorization is that there are some individuals who do not clearly fit in a category, and need to be dropped from the sample. Even when customers are placed it a category, they may have some traits of people in other categories. Hence, our approach which accepts that people's values lie in a broad space of four dimensions, and looks at the relationship between their dimension scores and CSR preferences will provide a better understanding of the underlying model.

Differences in the CSR assessment between people belonging to different value groups in different cultures. 
The next step in the analysis was to study whether values of individuals in different cultures impacted their preference for the CSR initiative. The results are presented in Table 1.

Table 1: Relationship between Values and CSR Preferences-No Promotion

\begin{tabular}{|c|c|c|c|}
\hline Regression Statistics & & & \\
\hline & USA & $\begin{array}{l}\text { ASIA } \\
\text { (Taiwan) }\end{array}$ & $\begin{array}{l}\text { Europe } \\
\text { (Poland) }\end{array}$ \\
\hline R squared & 0.1593 & 0.1897 & 0.097 \\
\hline $\mathrm{F}$ & 2.46 & 5.328 & 9.036 \\
\hline Significance & $5 \%$ & 0.00067 & $0 \%$ \\
\hline Intercept & 1.830493 & 1.226344467 & 3.887201888 \\
\hline Self-enhancement & -0.20946 & 0.047801539 & -0.013881548 \\
\hline Openness to change & 0.30411 & 0.281871754 & 0.103583676 \\
\hline Self-transcendence & 0.393841 & 0.422622956 & 0.286311623 \\
\hline Conservative & 0.330478 & 0.16085912 & 0.152848958 \\
\hline
\end{tabular}

The null hypothesis, $\mathrm{H} 1$ is rejected when there is no promotion of the CSR initiative by the company. We can conclude that there are differences between people's reactions to CSR announcements based on their values and there are differences based on national cultures.

The results show that there is a relationship between personal values and the response to CSR initiatives without a strong corporate communications program advertising the good work. All the regressions are significant. People who either self-transcendent, conservative, or open to change values prefer CSR programs that are not advertised, with selftranscendence values being the strongest indicator of a preference for CSR in all cultures. People who hold strongly self-enhancing values do not see much value in CSR programs that are not advertised.

Two things stand out from the regression. The first is the statistically significant difference between the intercepts of the regression. Our study subjects in Europe (Poland) had a much stronger preference for CSR initiative not promoted by the company in an ad campaign than in the USA and Asia (Taiwan). This is a clear national culture based phenomenon where there is strong belief in the need for business to conduct CSR programs. This is the floor of support for altruistic (non-advertised) CSR in the culture.

Another set of results shows support for hypothesis 2. Self-transcendent views strong influence positive attitudes towards CSR. This phenomenon occurs across cultures. One interesting issue which needs to be studied further is the shift in this narrative over time; i.e. do the preferences for CSR change over time as the result of demographic change or even a political campaign.

What about a campaign to promote the CSR initiative? Does this impact the opinions of subjects about CSR? Part of our subjects in each study, in Asia, Europe, and in the USA were provided a case with a description of the CSR initiative and the campaign to advertise and promote its CSR initiative. Data was analysed in a similar manner to the previous dataset. The results are shown in Table 2. Significant coefficients are highlighted. 
Marek Pawlak, Sathiadev Mahesh

Human Values and Reaction to CSR Announcements: A Cross-National Comparison with Emphasis on

U.S.-Global Differences

Table 2: Relationship between Values and CSR Preferences-After Promotion

\begin{tabular}{|l|r|r|r|}
\hline Regression Statistics & & & \\
\hline & \multicolumn{1}{|l|}{ USA } & ASIA (Taiwan) & $\begin{array}{l}\text { Europe } \\
\text { (Poland) }\end{array}$ \\
\hline & & & 0.1082 \\
\hline R squared & 0.116 & 0.1624 & 9.067 \\
\hline F & 1.7067 & 4.6045 & $0 \%$ \\
\hline Significance & $16 \%$ & $0.19 \%$ & \\
\hline & & & 3.470145549 \\
\hline Intercept & 1.00270808 & 2.567372187 & 0.035024927 \\
\hline Self-enhancement & 0.456608249 & -0.305825031 & 0.113733462 \\
\hline Openness to change & -0.055735081 & 0.493468615 & 0.348118668 \\
\hline Self-transcendence & 0.094281047 & 0.23904316 & 0.3146258 \\
\hline Conservative & 0.347588961 & 0.214025648 & 0.092134806 \\
\hline
\end{tabular}

In this case, $\mathrm{H} 1 \mathrm{~b}$ is rejected in Asia and Europe while it cannot be rejected in the USA. This is an interesting outcome. A strong promotion campaign about CSR initiatives drives scepticism about the sincerity of the business and washes out much of the values-driven difference in perception of CSR. In the USA group values did not have an impact on reactions to advertised CSR campaigns. Note that in TableI we showed that values had an impact in non-advertised CSR in the US. Since the USA data for this group is not significant, it is not meaningful to draw conclusions about differences in opinions about CSR based on values in this group.

The relationship is significant in Asia and Europe showing that campaigns to promote CSR can be effective when well managed. In addition to the intercept, which established the floor of support for CSR, people in Asia with strong openness to change values prefer CSR initiatives with corporate announcements while people in Europe with strong transcendent (altruistic) values prefer them.

Hypothesis 2 states that altruistic customers will evaluate CSR initiatives higher than non-altruistic. Altruistic customers will have strong self-transcending values and while this relationship is strong across cultures in Table I, i.e. for non-advertised CSR, the results are mixed in the case of advertised CSR. This lends us clear support for H2. A business which attracts altruistic customers by its branding and operational choices should maintain CSR programs, but should not advertise or seek to open gain benefits from these programs. Advertisement for these initiatives should emphasize their goals and not promote the business.

\section{Discussion}

\section{Conclusions and implications}

Studies about consumer response to CSR initiatives are ambiguous. While, Boulstridge and Carrigan (2000) conclude that there is a high level of scepticism about corporate charity. Schmeltz (2012) uses her data to claim that scepticism is lower than suggested by the prior literature. This difference may result from differences in the demographics of the groups studied. The results presented in our study confirm the hypothesis that values influence response to CSR announcement, provided the announcements do not promote the company conducting the CSR initiative. When the company promotes the initiative, there is less support for the initiative in all cultures, and in the case of the USA, there is no significant difference in the low level of support based on individual values.

The goal of this study was to examine the relationship between human values and opinions about CSR. The results enable us to formulate some additional conclusions:

- $\quad$ There are statistically significant differences between people belonging to different value groups in their opinion about CSR, but only if the company does not promote the initiative.

- $\quad$ If the company promotes itself as part of the CSR initiative, national cultural differences play a much larger role in opinions about CSR than personal values. 
- If the company issues an announcement about the social initiative to the public, then the assessment of this initiative decreases, especially among altruistic customers in the USA and Taiwan.

- $\quad$ The studies enable us to formulate some conclusions which can be helpful for managers of companies engaging in different social initiatives. Information about the company's social engagements never improves people's opinion about the initiative. Therefore, companies who want to inform people about their engagement should use indirect information channels. The company should measure national opinions about CSR and this floor of support is a major factor in evaluating the value of CSR. We wish to re-iterate that this floor of support is not constant, and we have no evidence to prove that this will not change with social and political currents. Since national culture itself is dependent on the impact on individual values of social and political changes accumulated over time, it is only logical to conclude that the floor of support for CSR needs to be evaluated before the program is initiated.

The results obtained also suggest that, although there are different opinions about social initiatives in different cultures (countries), people's responses to CSR announcements are actually similar when there is no corporate self-promotion apparent in the initiative.

\section{Limitations and future research}

The research presented here has many limitations. It must be stressed that only the opinions of groups of young students were collected here, but these people are not the only customers and receivers of CSR announcements. Secondly, the groups studied in some countries were too small to draw statistically significant conclusions. It is also not clear if the social problem presented - child malnutrition - was properly chosen, as it is not known to what extent this problem occurs in every country studied. While child malnutrition may be cursorily viewed as a third-world problem, even developed economies have a frayed social net, childhood hunger is a problem across the developed (Kotler, p.65), and developing world.

This also enables us to formulate some ideas for future research. This kind of study should also be performed on groups of older people, not only students; Opinions should be collected very carefully. The same conditions should be observed when collecting the opinions of different groups of people. The social initiative should be chosen very carefully. It should be an initiative which is responding to a problem which occurs in every country (town) studied. This study also suggests that, when describing the social initiative, we should not supply the name of the company. If we supply the name of the company we will end up studying an image of this company, but not the opinions about the CSR.

\section{References}

- $\quad$ Amaeshi, K. M. and B. Adi, (2007), 'Reconstructing the Corporate Social Responsibility Construct in Utlish', Business Ethics European Review (Chichester, England) 16, 3-18, CrossRef

- Arvidsson Susanne, (2010), Communication of Corporate Social Responsibility: A study of the Views of Management Teams in Large Companies, Journal of Business Ethics, Vol. 96, pp. 339-354, CrossRef

- $\quad$ Bardi Anat, Schwartz Shalom H., (2003), Values and Behavior: Strength and Structure of relations, Personality and Social Psychology Bulletin, Vol. 29, No. 10, pp. 1207-1220, CrossRef

- Benoit-Moreau Florence, Parguel Beatrice, (2011), Building brand equity with environmental communication: an empirical investigation in France, EuroMed Journal of Business, Vol. 6, No. 1, pp. 100-116

- $\quad$ Birth Gregory, Illia Laura, Lurati Judge, Zamparini Alessandra, (2008), Comunicating CSR: practices among Swizerland's top 300 companies, Corporate Communications: An International Journal, Vol. 13, No. 2, pp. 182196.

- Boulstridge Emma and Carrigan Marylyn (2000), Do consumers really care about corporate responsibility? Highlighting the attitude-behaviour gap. Journal of Communication Management, Vol. 4, No. 4, pp. 355-368, CrossRef

- $\quad$ Braccio Hering, B. (2013). Tactics for Team Building. (cover story). Managing People At Work, (377), 1.

- Buhman Karin, (2006), Corporate Social responsibility: what role for law? Some aspects of law and CSR, Corporate Governance, Vol. 6, No. 2, pp. 188-202, CrossRef

- Chen Hua, Zhang Haibin, (2009), Two-way communication strategy on CSR information in China, Social Responsibility Journal, Vo. 5, No. 4, pp. 2009 
- Davidov Eldad, (2010), Testing for comparability of human values across countries and time with the third round of the European Social Survey, International Journal of Comparative Sociology, 51(3) pp. 171-191, CrossRef

- $\quad$ Davidov Eldad, De Beuckelaer Alain, (2010), How Harmful are Survey Translations? A Test with Schwartz's Human Values Instrument, International Journal of Public Opinion Research, Vol. 22, No. 4, pp. 485-510 $\underline{\text { CrossRef }}$

- $\quad$ Davis Derick, MacDonald Jason B., (2010), Improving the Promotion of CSR Initiatives: A Framework for Understanding Stakeholder Communications from a Dynamic Learning Perspective, Academy of Marketing Studies Journal, Vol. 15, No. 2, pp. 77-93

- $\quad$ Ellen Pam Scholder, Webb Deborah J., Mohr Lois a., (2006), Building Corporate Associations: Consumer Attributions for Corporate Socially Responsible Programs, Journal of the Academy of Marketing Science, Vol. 34, No. 2, pp. 147-157, CrossRef

- $\quad$ European Commission (2002), Corporate Social Responsibility: A Business Contribution to Sustainable Development, Office for Official Publications of the European Communities, Luxemburg.

- $\quad$ Evans W. Randy, Davis Walter D., (2011), An Examination of Perceived Corporate Citizenship, Job Applicant Attraction, and CSR Work Role Definition, Business \& Society, Vol. 50, No. 3, pp. 456-480, CrossRef

- $\quad$ Farache Francisca, Perks Keith J., (2010), CSR advertisements: a legitimacy tool? Corporate Communications: An International Journal. Vol. 15, No. 3, pp. 235-248, CrossRef

- Fassin Yves, Buelens Marc, (2011), The hypocrisy-sincerity continuum in corporate communication and decision making. A model of corporate social responsibility and business ethics practices, Management Decision, Vol. 49, No. 4, pp. 586-600, CrossRef

- $\quad$ Fischer Ronald, Schwartz Shalom, (2011), Whence Differences in Value Priorities? Individual, Cultural or Artifactual Sources, Journal of Cross-Cultural Psychology, Vol. 42, No. 7, pp. 1127-1144, CrossRef

- Friedman Milton, (1970), The Social Responsibility of Business is to Increase its Profits, The New York Times Magazine, September 13.

- $\quad$ Fritzsche David J., Oz Effy, (2007), Personal Values' Influence on the Ethical Dimension of decision Making, Journal of Business Ethics, Vol. 75, pp. 335-343, CrossRef

- Glazer Sharon, Beehr Terry A., (2002), Similarities and Differences in Human Values between Nurses in Four Countries, International Journal of Cross Cultural Management, Vol. 2, No. 2, pp. 185-202, CrossRef

- $\quad$ Glaser Sharon, Daniel Carole Sophie, Short Kenneth M., (2004), A study of the relationship between organizational commitment and human values in four countries, Human Relations, Vol. 57, No. 3, pp. 323-345 $\underline{\text { CrossRef }}$

- Golob Ursa, Podnar Klement, Elving Wim J., Nielsen Anne Ellerup, Thomsen Christa, Schultz Frederike, (2013), CSR communication: quo vadis? Corporate Communication: An International Journal, Vol. 18, No. 2, pp. 176192, CrossRef

- González-Rodríguez María Rosario, Díaz-Fernández María Carmen, Pawlak Marek, Simonetti Biagio, (2013), Perceptions of students university of corporate social responsibility, Quality \& Quantity, 47:2361-2377, CrossRef

- Groves Kevin, LaRoca Michael A, (2012), Follower Beliefs in Corporate Social Responsibility? A Field study of Leader Personal Values and Follower Outcomes, Journal of Leadership \& Organizational Studies, Vol. 19, No. 2, pp. 215-229, CrossRef

- $\quad$ Groza Mark, D., Pronschinske Mya R., Walker Matthew, (2011), Perceived Organizational Motives and Consumer Responses to Proactive and reactive CSR, Journal of Business Ethics, Vol. 102, pp. 639-652, CrossRef

- Hartman Laura P., Rubin Robert S., Dhanda K. Kathy, (2007), The Communication of Corporate Social Responsibility: United States and European Union Multinational Corporations, Journal of Business Ethics, No. 74, pp. 373-389, CrossRef

- Knoppen Desiree, Saris Willem, (2009), Do we have to combine Values in the Schwartz' Human Values Scale? A Comment on the Davidov Studies, Survey Research Methods, Vol. 3, N. 2 pp. 91-103

- $\quad$ Koivula Nina, (2008), Basic Human Values in the Workplace, Social psychological studies 17, Department of Social Psychology, University of Helsinki, Helsinki

- $\quad$ Kotler Philip, Lee Nancy, (2005), Corporate Social Responsibility: Doing the Most Good for Your Company and Your Cause, Wiley, Hoboken, New York. 
- $\quad$ Liem Gregory Arief D., Martin Andrew J., Nair Elizabeth, Bernardo Allan B. I., Prasetya Paulus Hidajat, (2011), Content and Structure of Values in Middle Adolescence: Evidence From Singapore, The Philippines, Indonesia, and Australia, Journal of Cross-Cultural Psychology, Vol. 42, No. 1, pp. 146-154, CrossRef

- Nan Xiaoli, Heo Kwagjun, (2007), Consumer Responses to Corporate Social Responsibility (CSR) Initiatives, Journal of Advertising, Summer 2007, 36, 2, pp. 63-74, CrossRef

- $\quad$ Nielsen Anne Ellerup, Thomsen Christa, (2007), Reporting CSR - what and how to say it?, Corporate Communications: An International Journal, Vol. 12, No. 1, pp. 25-40, CrossRef

- Nielsen Anne Ellerup, Thomsen Christa, (2009), CSR communication in small and medium-sized enterprises. A study of the attitudes and beliefs of middle managers, Corporate Communications: An International Journal, Vol. 14, No. 2, pp. 176-189.Parguel Beatrice, Benoit-Moreau Florence, Larceneux Fabrice, (2011), How Sustainablility Ratings Might Deter 'Greenwashing': A Closer Look at Ethical Corporate Communication, Journal of Business Ethics, Vol. 102, pp. 15-28

- $\quad$ Perrinjaquet Amandine, Furrer Olivier, Usunier Jean-Claude, Cestre Ghislaine, Valette-Florence Pierre, (2007), A test of the quasi-circumplex structure of human values, Journal of Research in Personality, Vol. 41, pp. 820-840 CrossRef

- $\quad$ Pomering Alan, Dolnicar Sara, (2008), Assessing the Prerequsite of Successful CSR Implementation: Are Consumers Aware of CSR Initiatives? Journal of Business Ethics, Vol. 85, pp. 285-301

- $\quad$ Pomering Alan, Johnson Lester W., (2009), Advertising corporate social responsibility initiatives to communicate corporage image. Inhibiting skepticism to enhance persuasion, Corporate Communications: An International Journal, Vol. 14, No. 4, pp. 420-439.

- $\quad$ Pomering Alan, Johnson Lester W., (2009), Constructing a corporate social responsibility reputation using corporate image advertising, Australian Marketing Journal, Vol. 17, No. 2, pp. 106-114, CrossRef

- Quairel-Lanoizelée Francoise, (2011), Are competition and corporate social responsibility compatible? The myth of sustainable competitive advantage, Society and Business Review, Vol. 6, No. 1, pp. 77-98, CrossRef

- $\quad$ Reynolds Mary Ann, Yuthas Kristi, (2007), Moral Discourse and Corporate Social Responsibility Reporting, Journal of Business Ethics, Vol. 78 pp. 47-64

- $\quad$ Roberts Claire, Rapson Dan, Shiers David, (2007), Social Responsibility : key terms and they uses in property investment, Journal of Property Investment \& Finance, Vol. 25, No. 4, pp. 388-400, CrossRef

- $\quad$ Roccas Sonia, Sagiv Lilach, Schwartz Sahlom H., Knafo Ariel, (2002), The Big Five Personality Factors and Personal Values, Personality and Social Psychology Bulletin, Vol. 28, No. 6, pp. 789-801, CrossRef

- $\quad$ Runhaar Hens, Lafferty Helene, (2009), Governing Corporate Social Responsibility: An Assessment of the Contribution of the UN Global Compact to CSR Strategies in the Telecommunications Industry, Journal of Business Ethics, Vol. 84, pp. 479-495, CrossRef

- Sagiv Lilach, Schwartz Shalom H., (2004), Values, intelligence and client behavior in career counseling, European Journal of Psychology of Education, Vol. XIX, No. 3, pp. 237-254

- $\quad$ Schmeltz Line, (2012), Consumer-oriented CSR communication: focusing on ability or morality?, Corporate Communications: An International Journal, Vol. 17, No. 1, pp. 29-49, CrossRef

- Schwartz Shalom H., Sagie Galit, (2000), Value Consequences and Importance: A Cross-National Study, Journal of Cross-Cultural Psychology, Vol. 31, No. 4, pp. 465-497, CrossRef

- Schwartz Shalom H., (2006), Basic Human Values: Theory, measurement, and applications, Revue Françoise de sociologie, 42, 249-288

- $\quad$ Schwartz Shalom H., (2011), Studying Values: Personal Adventure, Future Directions, Journal of Cross-Cultural Psychology, Vol. 42, No. 2, pp 307-319, CrossRef

- $\quad$ Smith Wanda J., Wokuth Richard E., Harrington K. Vernard, Dennis Bryan S, (2001), An Examination of the Influence of Diversity and Stakeholders Role on Corporate Social Orientation, Business \& Society, Vol. 40, No. 3, pp. 266-294, CrossRef

- $\quad$ Struch Noami, Schwartz Shalom H., van der Kloot Willem A., (2002), Meanings of Basic Values for Women and Men, Personality and Social Psychology Bulletin, Vol. 28, No. 1, pp. 16-28, CrossRef

- $\quad$ Swaen V. and Vanhamme J. (2004), "The use of corporate social responsibility arguments in communication campaigns: Does source credibility matter?", In Menon, G. and A. R. Rao (Eds.), Advances in Consumer Research, Vol. XXXII, Portland, USA, October 7-10, pp. 590-591. 
- $\quad$ Tixier Maud, (2003), Soft vs. Hard Approach in Communicating on Corporate Social Responsibility, Thunderbird International Business Review, Vol. 45, No. 1, pp. 71-91, CrossRef

- Van der Wal Zeger, Huberts Leo, (2008), Value Solidity in Government and Business. Results of an Empirical Study on Public and Private Sector Organizational Values, The American Review of Public Administration, Vol. 38, No. 3, pp. 264-285, CrossRef

- V Vanhamme Joëlle, Grobben Bas, (2008), "Too Good to be True!". The Effectiveness of CSR History in Countering the Negative Publicity, Journal of Business Ethics, No. 85, pp. 273-283.

- Wang Alex, Anderson Ronald B., (2011), A Multi-Staged Model of Consumer Responses to CSR Communications, The Journal of Corporate Citizenship, Vol. 41, pp. 51-68

- Wang Lei, Juslin Heikki, (2012), Values and Corporate Social Responsibility Perceptions of Chinese University Students, Journal of Academic Ethics, Vol. 10, Issue 1, pp. 57-82 